\title{
Fibreoptic endoscopy and the use of the Sengstaken tube in acute gastrointestinal haemorrhage in patients with portal hypertension and varices
}

\author{
B. H. NOVIS, ${ }^{1}$ P. DUYS, G. O. BARBEZAT, J. CLAIN, S. BANK, AND \\ J. TERBLANCHE
}

From the Gastrointestinal Clinic and the MRC/UCT Liver Research Group, Departments of Medicine and Surgery, Groote Schuur Hospital and the University of Cape Town, Cape Town, South Africa

SUMMARY The value of emergency upper gastrointestinal fibre-endoscopy, followed where required by the use of a modified Sengstaken tube, was studied during 84 episodes of acute bleeding in 75 patients who had evidence of portal hypertension with varices. The portal hypertension was due to alcoholic cirrhosis in $80 \%$ and to cryptogenic cirrhosis in $9 \%$ of the patients. By definition, varices were present in all patients, but in only $66 \%$ of episodes were the varices the cause of the bleed. The correct diagnosis of the source of bleeding was made at endoscopy in $89 \%$. A Boyce modification of the Sengstaken-Blakemore tube was passed in $73 \%$ of the episodes of variceal bleeding. It effectively stopped the bleeding primarily in $85 \%$ of patients but was successful as a final definitive measure only in $46 \%$. Furthermore, only $40 \%$ of the patients in whom the tube was passed, survived. Mortality rate could be related to the severity of the bleed and to hepatocellular dysfunction. Survival increased from $23 \%$ in those patients with jaundice, ascites, and encephalopathy on admission to $92 \%$ in those without these manifestations. The in-hospital survival rate was $52 \%$ in patients bleeding from varices and $64 \%$ in those bleeding from other causes, with an overall survival rate of $56 \%$, indicating the poor prognosis in cirrhotic patients with gastrointestinal bleeding, irrespective of the cause.

The Sengstaken-Blakemore tube has been used in the management of bleeding oesophageal varices for many years (Sengstaken and Blakemore, 1950; Brick and Palmer, 1964). The high mortality, despite its use, led to condemnation of the tube, which became less popular for some years (Conn and Simpson, 1967). This was occasioned partly by the alleged therapeutic value of pitressin (Shaldon and Sherlock, 1960), but more probably because of the tube's failure to control bleeding, due to misdiagnosis when a lesion other than varices was the source of bleeding in patients with portal hypertension, and because of complications due to mismanagement of the tube. The recent advent of upper gastrointestinal fibreoptic panendoscopy and its increasing use in patients known to have, or suspected to be,

\footnotetext{
${ }^{1}$ Address for correspondence and reprint requests: $\operatorname{Dr}$ B. H. Novis, c/o Gastrointestinal Clinic, Groote Schuur Hospital, Observatory 7925, Cape Town, South Africa.

Received for publication 19 January 1976
}

bleeding from oesophageal varices has assisted in delineating the actual site of the bleeding and hence the exact indication for compression therapy with the tube.

Although the Sengstaken-Blakemore (SB) tube is being used more frequently in the initial management of variceal bleeding, there have been only a few (Waldram et al., 1973) well-documented prospective studies of its use, following a definitive diagnosis being made at endoscopy of the whole upper gastrointestinal tract.

Dissatisfaction with the non-standardized management policy at our hospital during the period $1968-71$, in which only $60 \%$ of 82 patients had their varices confirmed during the emergency admission and only $15 \%$ had a SB tube passed, with a high complication and mortality rate (Terblanche et al., 1974), led us to undertake a prospective study of the value of endoscopy in establishing the cause of bleeding and an analysis of the usefulness of a modified SB tube in controlling the bleeding in patients 
with portal hypertension and varices admitted during the period 1972-74.

A review of these patients forms the basis of this paper.

\section{Patients}

All patients admitted to the hospital with acute gastrointestinal haemorrhage and clinical evidence of portal hypertension who were subsequently shown to have varices were included. Seventy-five patients were studied during 84 episodes of acute bleeding. There were 60 males and 15 females. Fifty-one patients were Caucasians, 18 Mulattos, and six Africans. Their ages ranged from 16 to 86 years.

\section{Methods}

All patients were immediately resuscitated. Treatment included transfusion with whole blood and an intravenous infusion of 20 units pitressin in $278 \mathrm{~m} \mathrm{M} \mathrm{5 \%}$ dextrose solution. Once stabilized, all patients had endoscopy with an Olympus GI F-D forwardviewing fibrescope, after iced saline gastric lavage (this was omitted in the latter two years). With the patient in the left lateral position, an intern or nurse ensured that the mouth was aspirated free of blood and secretions. The pharynx was anaesthetized with $4 \%$ lignocaine spray. Atropine, $0.6 \mathrm{mg}$, was given intravenously with diazepam. Most patients were adequately sedated with between 5 and $10 \mathrm{mg}$ diazepam, but alcoholic patients often required larger doses and even this was not invariably effective. In these cases, intravenous haloperidol, $4-8 \mathrm{mg}$, or clotiapine, $40-80 \mathrm{mg}$, was occasionally used with some success. In two patients, a general anaesthetic was required. Care was taken to prevent dislodgement of any clots attached to the varices. In all cases, a full examination of the upper gastrointestinal tract was made, except in six episodes when the endoscope was not manoeuvred past varices from which blood was spurting. If variceal bleeding were diagnosed, a SB tube with Boyce modification was immediately passed. This modification consists of a SB tube to which a Ryle's tube is attached for oesophageal toilet (Boyce, 1962).

The gastric balloon was inflated with $200 \mathrm{ml}$ of air and $20 \mathrm{ml}$ Hypaque and positioned by firm traction on the tube. The oesophageal balloon was inflated to a pressure of $25-45 \mathrm{~mm} \mathrm{Hg}$ utilizing the lowest pressure required to control bleeding. The SB tube was maintained in place and on tension by passing the proximal end through a spliced tennis ball which was fixed to the cheek by plaster strips. The general management of the SB tube was carried out as described by Pitcher (1971). All patients were nursed in a medical ward under the constant supervision of a trained attendant. Balloon inflation was maintained for 24-36 hours and then the oesophageal balloon only was deflated. If rebleeding occurred, traction was reapplied and the oesophageal balloon reinflated for a further 24 hours. All patients were treated for liver failure with intragastric neomycin and lactulose administered via the SB tube.

\section{Results}

\section{AETIOLOGY}

Eighty percent of the patients had alcoholic cirrhosis and $9 \%$ had cryptogenic cirrhosis. The remaining causes of portal hypertension are shown in Table 1.

\section{ENDOSCOPY}

By definition, for inclusion in the study, varices were present in all 75 patients in the 84 episodes of bleeding. However, only $56(66 \%)$ episodes of bleeding were diagnosed as being due to the varices. In the majority $(70 \%)$ of these 56 patients the diagnosis of bleeding from varices was proven by noting blood spurting from a varix or, more usually, fresh clot on a varix, with blood oozing out. In the remaining $30 \%$ the variceal bleeding was inferred by finding ulceration on a varix or copious amounts of blood welling up in the lower oesophagus in the absence of any other definite source of bleeding on panendoscopy.

The sources of bleeding in the 28 episodes where bleeding originated from a site other than varices is shown in Table 2. Furthermore, a second lesion, apart from the varices, which was not the site of the bleeding was present on 21 occasions and, in four of these, two additional lesions were seen. This secondary lesion was gastric erosions in 13 episodes, duodenal erosions in five, gastric ulcer in one, oesophagitis in one, and extrinsic pressure in one.

As far as could be judged by the subsequent

\begin{tabular}{ll}
\hline Aetiology & No. of patients \\
\hline Cirrhosis & \\
Alcoholic & 59 \\
Cryptogenic & 7 \\
Post-necrotic & 1 \\
Cardiac & 1 \\
Porphyria & 1 \\
Budd-Chiari syndrome & 1 \\
Portal vein thrombosis & 2 \\
Splenic vein thrombosis & 1 \\
Congenital hepatic fibrosis & 1 \\
Haemochromatosis & 1 \\
Total & 75 \\
\hline
\end{tabular}

Table i Causes of portal hypertension in 75 patients 


\begin{tabular}{lc}
\hline Cause of bleed & No. of episodes \\
\hline Varices & 56 \\
Erosions & 9 \\
Ulcer & 7 \\
$\quad$ Duodenal & 5 \\
Gastric & 2 \\
Mallory-Weiss tear & 2 \\
Oesophagitis & 1 \\
Erosion + varix & 2 \\
No cause found & 84 \\
Total & \\
\hline
\end{tabular}

Table 2 Sites of bleeding in 84 episodes of acute upper gastrointestinal haemorrhage

clinical course and the findings at surgery or necropsy, the correct diagnosis of the source of bleeding was made at endoscopy in $89 \%$ of the episodes. On three occasions, the patient was falsely assessed to be bleeding from varices and in three falsely diagnosed as bleeding from other lesions. In three episodes, the site of bleeding (erosions twice and an ulcer once) was missed at endoscopy.

Complications occurred in two patients during endoscopy. One patient, bleeding torrentially and nearly moribund at the start of endoscopy, died during the procedure, and a second who had seemingly stopped bleeding, had a 2 litre haematemesis during the procedure and became semicomatose. In a few alcoholic patients, moderate to severe confusion followed endoscopy, due possibly to the diazepam. Aspiration and bronchopneumonia were recorded in seven patients but whether produced by endoscopy or incorrectly managed SB tube tamponade was difficult to ascertain.

SENGSTAKEN-BLAKEMORE TUBE

The modified SB tube was passed in $41(73 \%)$ of the 56 episodes of variceal bleeding in which there was evidence at endoscopy of continued bleeding and thus failure of the bolus of pitressin to effect haemostasis. A flow chart indicating the outcome of these episodes is presented in the Figure. The tube stopped the bleeding initially in 35 episodes $(85 \%)$ usually as soon as the balloons were inflated. The bleeding restarted after removal of the tube in $21(60 \%)$ of the 35 episodes, in 10 within 72 hours, and in 11 after 72 hours; the tube was not reinserted in seven of the 21 and all these patients subsequently died. The tube was reinserted in eight and, in six of these, the bleeding again stopped. In these six patients, three again re-bled; surgery was carried out in one, the tube was reinserted in two for a third time. Only one of these three survived the admission. In four episodes where bleeding had restarted after initial removal of the tube, the bleeding stopped with conservative measures and two were referred for surgery. In six episodes, the SB tube did not stop the bleeding at all and three of these were operated on immediately.

Final control of bleeding by the SB tube was achieved in $19(46 \%)$ of the episodes in which the tube was inserted. However, in these 41 bleeding episodes, 25 patients $(60 \%)$ died (often from causes other than bleeding). Emergency surgery was performed in a total of nine patients, five of whom died post-operatively.

The SB tube was not passed in 15 episodes due to variceal bleeding as the bleeding had clearly stopped (possibly due to the use of pitressin) at the time of endoscopy. Bleeding restarted in only two of these with a fatal outcome in both. In general, the episodes in which the tube was not passed had been much smaller bleeds, as evidenced by the fact that these patients received an average of 11 units of blood, compared with 18 units in those in whom the tube was passed.

Complications due to the SB tube occurred in 12 patients. Five patients aspirated, four were unable to retain the tube and pulled it out, and three developed bronchopneumonia.

\section{PROGNOSIS}

When related to the severity of the bleeding episodes, the mortality rate increased from four out of 18 $(22 \%)$ in patients requiring from 3-9 units of blood to be transfused, to 15 out of $26(58 \%)$ in those needing from 10-20 units of blood.

The other factor influencing the outcome of emergency management in the individual patients and the one and two year survival rate was the hepatocellular function as indicated by the presence, on admission, of the clinical triad of jaundice, ascites, and hepatic encephalopathy, and the level of the serum albumin (see Table 3). Fifty per cent of the patients in this study had evidence of hepatic failure as indicated by encephalopathy or at least two signs of the triad.

In patients bleeding from varices but without the clinical triad, the survival rate during that admission was 12 out of $13(92 \%)$. All five patients with presinusoidal portal hypertension and good hepatocellular function survived. If one feature of the triad were present, the survival rate dropped to nine out of $17(53 \%)$. When two features of the triad were present, the survival rate was five out of 13 $(38 \%)$, and when the full triad was present only three out of $13(23 \%)$ survived. Thus, $75 \%$ of the patients who died had some degree of hepatic decompensation at the time of admission.

The serum albumin level on admission had similar prognostic significance. Eighteen out of $26(69 \%)$ of the patients with a level greater than $30 \mathrm{~g} / 1$ 


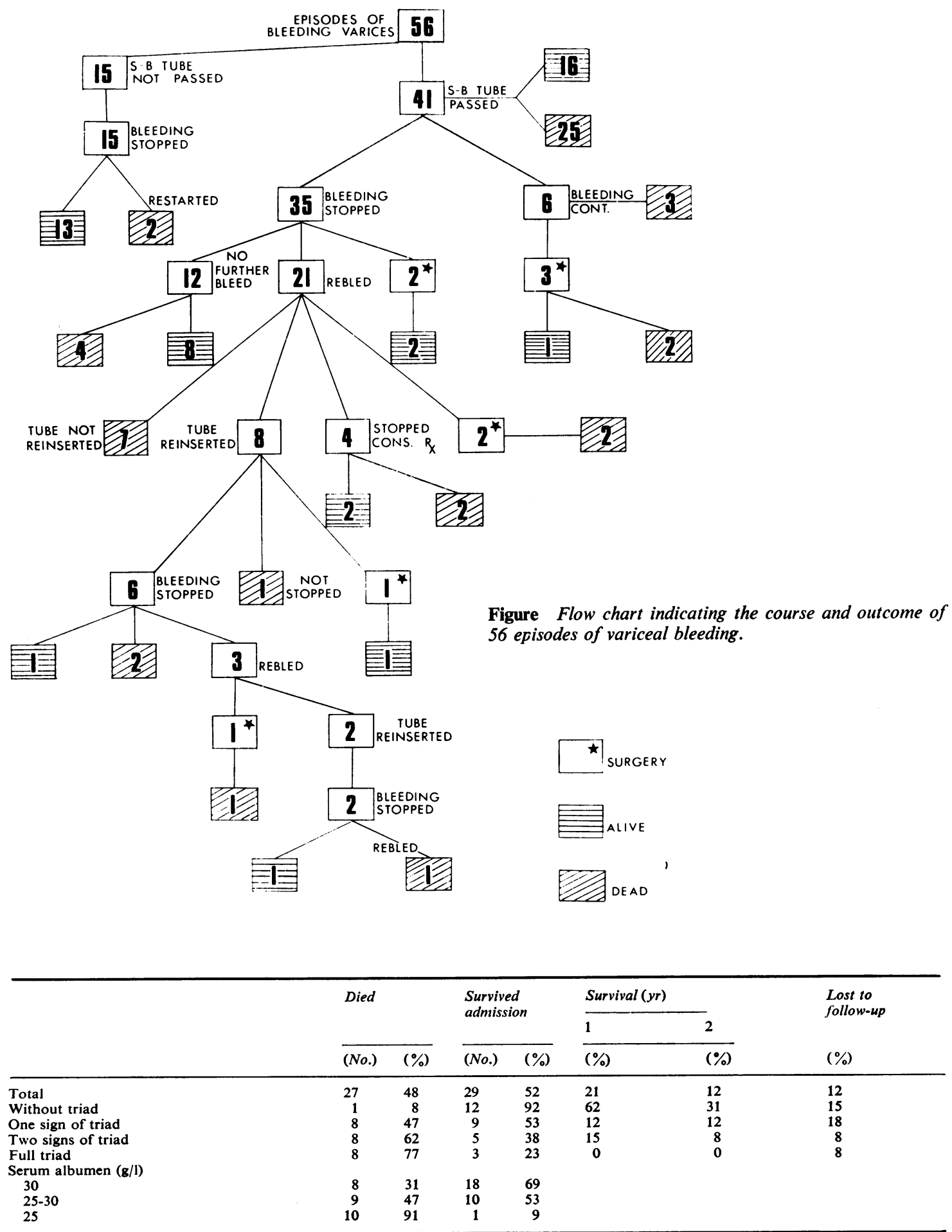

Table 3 Prognosis of patients bleeding from varices according to hepatocellular function 
survived, whereas 10 out of $19(53 \%)$ with a level of $25-30 \mathrm{~g} / \mathrm{l}$ and only one out of $10(9 \%)$ with a level less than $25 \mathrm{~g} / \mathrm{l}$ survived.

\section{OUTCOME}

The in-hospital survival rate of those patients bleeding from varices was $52 \%(29 / 56)$. The cause of death in nine patients was a combination of hepatic failure with repeated or continued haemorrhage. Hepatic failure without further bleeding accounted for six deaths. Pulmonary complications in association with one of the above occurred in three patients, and was the only cause of death in a further two patients. Two patients died in renal failure. Five patients died from continuous or repeated haemorrhage. The overall one year survival rate was $21 \%$, the overall two year survival rate was only $12 \%$, with $12 \%$ of patients being lost to follow up.

\section{NON-VARICEAL BLEEDS}

Of the 28 episodes in which the bleeding was due to associated gastrointestinal causes (see Table 2), $18(64 \%)$ patients survived and 10 died: seven from hepatic failure, one from pulmonary complications, one immediately after operation, and one from carcinomatosis. There were seven patients in this group who required surgery because of continuous bleeding: three from gastric erosions and two each from gastric and duodenal ulcer. All three operated on with bleeding gastric erosions died postoperatively and one each of the patients with a gastric and duodenal ulcer. The prognosis was influenced by the same factors as those of the variceal bleedersnamely, the severity of the bleeding episode and hepatocellular function. This is similar to the experience of others (Wirthlin et al., 1974).

The overall in-hospital survival rate in all patients with portal hypertension and variceal and nonvariceal bleeding was $56 \%(47 / 84)$.

\section{Discussion}

The necessity for an accurate diagnosis before assessing the usefulness of any technique in the management of bleeding varices has been stressed by Palmer (1969) and Pitcher (1971). Factually, this has become a reality only in recent years with the introduction of forward viewing fibreoptic panendoscopes which are able to view not only the oesophagus but the stomach and duodenum as well. The results of the present study indicate that the correct diagnosis of the cause of bleeding in patients with portal hypertension can be made in $89 \%$ of patients. The site of bleeding was not diagnosable for technical reasons in $4 \%$ and, in $7 \%$, a lesion was seen which was incorrectly diagnosed as the source of bleeding.
Previous studies have indicated that $33 \%$ or more of patients with oesophageal varices will be bleeding from an associated lesion (Palmer, 1969).

This prospective study has also shown the value of tamponade by SB tube as a primary measure to stop bleeding. Although two forms of therapy were used, pitressin given once in a dose of 20 units before endoscopy had, in fact, produced cessation of bleeding in only 15 episodes in which the SB tube was not subsequently passed. Bleeding was stopped as soon as tamponade was effected in $85 \%$ of episodes; the haemorrhage, however, restarted after removal of the SB tube in $60 \%$ of these, and tamponade was successful as a final definitive measure in $46 \%$ in controlling bleeding. A survival rate of $40 \%$ in patients requiring tamponade was achieved in this study. Thus, as in other studies, tamponade was followed by rebleeding and subsequent mortality in a high proportion of cases. Sheldon and Sherlock (1960) found that vasopressin (pitressin) given intravenously controlled bleeding from varices but was also followed by rebleeding in a high proportion of cases. Intra-arterial vasopressin was able to control variceal bleeding in $71 \%$ of cases but in $41 \%$ there was rebleeding on stopping the infusion, with a final survival of $47 \%$ (Conn et al., 1975). Raschke and Paquet (1973) had a 50\% mortality in 12 patients bleeding acutely from varices treated by oesophagoscopic sclerosing therapy, although the therapy had controlled bleeding in all but one patient. Johnston and Rodgers (1973) were able to control bleeding by sclerotherapy in $93 \%$ of admissions in 117 patients with an admission mortality of only $18 \%$. However, $25 \%$ of their patients had extrahepatic portal hypertension with good hepatic function. Pugh et al. (1973) reported a $55 \%$ mortality in patients treated for bleeding varices by trans-section of the oesophagus, although only $30 \%$ continued to bleed after operation (Pugh et al., 1973). The high mortality with surgery in the present series can be ascribed, at least partly, to the fact that surgery was performed as a last resort when other treatment had failed.

A high control rate of bleeding by the SB tube $(76 \%)$ has so far been reported only by Pitcher (1971) who achieved a $64 \%$ overall survival rate. This is almost double the mean survival rate for bleeding varices reported previously in the USA (Conn, 1971). The high success rate in Pitcher's study may be attributed to the high percentage $(60 \%)$ of patients considered to be good risk patients and the selection of 50 patients out of 126 who were managed personally by an experienced gastroenterologist. In the present series, $60 \%$ of the patients were considered to be bad risk patients, which probably accounts for the lower survival rate of $52 \%$ compared with that of Pitcher's series and to the $56 \%$ in Sherlock's 
(1965) study where only a third of the patients could be considered to be poor risks.

This study has again shown that the limiting factor in the treatment of patients bleeding from varices is not so much the ability to control the bleeding temporarily, but to the defects in the hepatocellular function and subsequent coagulation, cerebral, hepatic, renal, and electrolyte problems. As Conn has stated (Conn et al., 1975), SB tamponade cannot be viewed as an isolated form of therapy in bleeding varices but represents a single link in the chain of therapy. Thus, in the patient with good hepatocellular function, successful tamponade becomes important, as these are the patients who are likely candidates for a relatively good result from portosystemic shunts or sclerotherapy of the varices (Johnston and Rodgers, 1973). On the other hand, the prognosis for survival of patients with hepatocellular decompensation is poor for the immediate admission and abysmal for one and two year survival.

Patients with varices, but who were bleeding from associated lesions, had a slightly better prognosis. This, together with the need for different therapy, emphasizes the importance of a correct early diagnosis. This group had a survival rate of $64 \%$ compared with $52 \%$ in those bleeding from varices. This survival was still much lower than the $95 \%$ in patients with gastrointestinal haemorrhage but without evidence of portal hypertension in our hospital over the same period (Novis et al., 1975) and indicates the poor prognosis in cirrhotic patients with gastrointestinal bleeding, irrespective of cause.

This study lends strong support to the argument that endoscopy is the procedure of choice in establishing the exact site of bleeding in patients with portal hypertension. It has also been shown that, although the SB tube can be used safely and is initially helpful in stopping variceal bleeding, the final outcome will depend more on the patients' hepatic function and reserve, and whether further bleeds occur, than on the method employed in arresting the initial bleed.

\section{References}

Boyce, H. W., Jr (1962) Modification of the Sengstaken-
Blakemore balloon tube. New England Journal of Medicine, 267, 195-196.

Brick, I. B., and Palmer, E. D. (1964). One thousand cases of portal cirrhosis of the liver. Archives of Internal Medicine, (Chic.), 113, 501-511.

Conn, H. O., and Simpson, J. A. (1967). Excessive mortality associated with balloon tamponade of bleeding varices. Journal of the American Medical Association, 202, 587-591.

Conn, H. O. (1971). Sengstaken-Blakemore tube revisited. Gastroenterology, 61, 398-400.

Conn, H. O., Ramsby, G. R., Storer, E. H., Mutchnick, M. G., Joshi, P. H., Phillips, M. M., Cohen, G. A., Fields, G. N., and Petroski, D. (1975). Intra-arterial vasopressin in the treatment of upper gastrointestinal hemorrhage; a prospective, controlled clinical trial. Gastroenterology, 68, 211-221.

Johnston, G. W., and Rodgers, H. W. (1973). A review of 15 years experience in the use of sclerotherapy in the control of acute haemorrhage from oesophageal varices. British Journal of Surgery, 60, 797-800.

Novis, B. H., Clain, J., Barbezat, G. O. and Bank, S. (1976). Urgent fibre-optic panendoscopy in upper gastrointestinal haemorrhage. South African Medical Journal, 50, 93-96.

Palmer, E. D. (1969). The vigorous diagnostic approach to upper gastrointestinal tract hemorrhage. Journal of the American Medical Association, 207, 1477-1480.

Pitcher, J. L. (1971). Safety and effectiveness of the modified Sengstaken-Blakemore tube: a prospective study. Gastroenterology, 61, 291-298.

Pugh, R. N. H., Murray-Lyon, I. M., Dawson, J. L., Pietroni, M. C., and Williams, R. (1973). Transection of the oesophagus for bleeding oesophageal varices. British Journal of Surgery, 60, 646-649.

Raschke, E., and Paquet, K. T. (1973). Management of hemorrhage from esophageal varices using the esophagoscopic sclerosing method. Annals of Surgery, 177, 99-102.

Sengstaken, R. W., and Blakemore, A. H. (1950). Balloon tamponade for the control of hemorrhage from esophageal varices. Annals of Surgery, 131, 781-789.

Shaldon, S., and Sherlock, S. (1960). The use of vasopressin ('Pitressin') in the control of bleeding from oesophageal varices. Lancet, 2, 222-225.

Terblanche, J., Saunders, S. J., and Louw, J. (1974). Cirrhosis of the liver: acute hepatic failure. In Surgical ForumThe Liver, pp. 1-35. Edited by R. Smith. Butterworths: London.

Sherlock, S. (1964). Haematemesis in portal hypertension. British Journal of Surgery, 51, 746-749.

Waldram, R., Davis, M., Nunnerly, H., and Williams, R. (1973). Emergency fibreendoscopy following acute gastrointestinal haemorrhage in patients with portal hypertension. Gut, 14, 920.

Wirthlin, L. S., van Urk, H., Malt, R. B., and Malt, R. A. (1974). Predictors of surgical mortality in patients with cirrhosis and non-variceal gastroduodenal bleeding. Surgery, Gynaecology and Obstetrics, 139, 65-68. 